OPEN ACCESS

Edited by:

Massimiliano Valeriani, Bambino Gesù Children Hospital (IRCCS), Italy

Reviewed by: Andrea Negro,

Sapienza University of Rome, Italy Fabio Antonaci,

University of Pavia, Italy

*Correspondence: Jasem Al-Hashe dralhashe/@hotmail.com jasemkumsa@hotmail.com

Specialty section:

This article was submitted to Headache Medicine and Facial Pain,

a section of the journa

Frontiers in Neurology

Received: 29 March 2019 Accepted: 15 May 2019

Published: 04 June 2019

Citation: Al-Hashel J, Ibrahim I, Youssry D, Ahmed SF and Goadsby P (2019)

Cluster Headache in Kuwait: $A$ Hospital-Based Study. Front. Neurol. 10:573. doi: 10.3389/fneur.2019.00573

\section{Cluster Headache in Kuwait: A Hospital-Based Study}

\author{
Jasem Al-Hashel ${ }^{1,2 *}$, Ismail Ibrahim ${ }^{1}$, Doaa Youssry ${ }^{1,3}$, Samar Farouk Ahmed ${ }^{1,4}$ and \\ Peter Goadsby ${ }^{5}$
}

${ }^{1}$ Department of Neurology, Ibn Sina Hospital, Kuwait City, Kuwait, ${ }^{2}$ Department of Medicine, Faculty of Medicine, Health Sciences Centre, Kuwait University, Kuwait City, Kuwait, ${ }^{3}$ Department of Neurology, Cairo University, Cairo, Egypt, ${ }^{4}$ Department of Neuropsychiatry, Minia University, Minia, Egypt, ${ }^{5}$ Department of Basic and Clinical Neuroscience, Headache Group, Institute of Psychiatry, Psychology and Neuroscience, King's College London, NIHR-Wellcome Trust King's Clinical Research Facility, King's College Hospital, London, United Kingdom

Background: Cluster headache $(\mathrm{CH})$ is a relatively uncommon primary headache disorder. Few studies in our region described $\mathrm{CH}$. We aimed to study demographics, clinical characteristics and treatment modalities of $\mathrm{CH}$ patients referred to Headache Clinic in Kuwait.

Materials and Methods: This cross-sectional study included all $\mathrm{CH}$ patients who are referred to headache clinic. The diagnosis of $\mathrm{CH}$ based on the $\mathrm{CH}$ diagnostic criteria of the Headache Classification Committee of the IHS, 3rd edition (beta version) (ICHD-3-beta). The demographics, clinical characteristics and treatment modalities of $\mathrm{CH}$ patients were recorded.

Results: Forty six patients were diagnosed with $\mathrm{CH}$ which constituted $1.7 \%$ of all headache patients and $0.1 \%$ of all visits to Neurology clinic. Male:Female ratio was 15.3:1. Mean age was $40.1 \pm 10.7$ years and mean age at onset was 29 years (20-49). Family history was positive in $6.5 \%$. Smoking was seen in $63.0 \%$ of patients while 6.5 $\%$ reported alcohol intake. $\mathrm{CH}$ was episodic in $84.4 \%$ and chronic in $15.2 \%$. Seasonal predilection was seen in all patients; the most frequent season was Autumn $47.8 \%$. The mean duration of the cluster bouts was 6 weeks (2-12 weeks). The mean duration of the attack was $60 \mathrm{~min}$ (15-180 min). Number of attacks per day ranged from 2 to 10 attacks with a mean of 5 attacks/day. The median of attack severity by Visual Analog Scale (VAS) was $8.5(7-10)$. The time taken to diagnose the patients ranged from $<1$ year to 12 years with a mean of 4 years. Chronic $\mathrm{CH}$ have a statically significant relation with smoking $(P=0.036)$, older age $(P=0.027)$, and longer time taken to diagnosis $(P=0.026)$ compared to episodic $\mathrm{CH}$.

Conclusion: Our results reported that there is higher proportion of males compared to females and less positive family history. Smoking was a significant risk factor for chronicity in addition to advanced age, higher age at disease onset and a longer time taken till diagnosis.

Keywords: cluster headache, demographics, trigeminal autonomic cephalalgias, hospital study, Kuwait 


\section{INTRODUCTION}

Cluster headache $(\mathrm{CH})$ is a relatively uncommon yet incapacitating primary headache disorder classified together with other similar conditions as Trigeminal Autonomic Cephalalgias (TAC) (1). The distinguishing features of $\mathrm{CH}$ include male predominance, periodic occurrence of cluster attacks (circannual and circadian periodicity), and concurrence of autonomic features $(2,3)$. The majority of the patients also describe sense of agitation and restlessness during the peak of the headache attack (1).

The attacks of headache tend to cluster in bouts, lasting between 15 and $180 \mathrm{~min}$, recurring from every other day to multiple times per day for weeks or months during active cluster bouts, followed by periods of remission $(1,4)$. In episodic $\mathrm{CH}$, the bouts often occur with a seasonal pattern separated by headache-free intervals, while in chronic $\mathrm{CH}$ the attacks recur for more than a year with no remission or with remission for $<3$ months $(1,5,6)$.

The pain associated with $\mathrm{CH}$ can be excruciating and has been described as the most severe pain known to humans $(7,8)$. Accordingly, the disease has substantial negative impact on social function and quality of life (9).

Few studies in our region described the prevalence and the clinical characteristics of $\mathrm{CH}$ and no studies were published from the Arabian Gulf region including Kuwait $(10,11)$.

We aimed to study demographics, clinical characteristics and treatment modalities of $\mathrm{CH}$ patients referred to our Headache Clinic at the only tertiary neurology center in Kuwait during the period from January 2016 to September 2018.

\section{MATERIALS AND METHODS}

This cross-sectional study included all $\mathrm{CH}$ patients who are referred to our headache clinic at the only tertiary neurology center in Kuwait. We reviewed the patient's data registry to identify those with the diagnosis of $\mathrm{CH}$ from January 2016, till September, 2018. The patients were contacted and scheduled for reassessment in our headache clinic. The diagnosis of $\mathrm{CH}$ was rechallenged and confirmed by headache specialist. All the patients that met the $\mathrm{CH}$ diagnostic criteria of the Headache Classification Committee of the IHS, 3rd edition (beta version) (ICHD-3-beta) (1) were included.

Each patient underwent a detailed clinical evaluation and neurological examination by a neurologist. Appropriate brain imaging was requested to rule out secondary headache causes. Demographic data included age, sex, nationality, family history of $\mathrm{CH}$, and history of smoking or alcohol abuse. $\mathrm{CH}$ information including type of $\mathrm{CH}$, attack characteristics (site, side, season, severity, character, duration of attack, duration of disease, duration of bouts, frequency), age at the onset, age at diagnosis,

Abbreviations: BTX, Botulinum toxin; $\mathrm{CH}$, Cluster Headache; GONB, Greater occipital nerve block; ICHD, International Classification of Headache Disorders; MR, Magnetic resonance; NSAID, Non-steroidal anti-inflammatory drugs; RFA, Radiofrequency ablation; SPG, Sphenopalatine ganglion; TACs, Trigeminal Autonomic Cephalalgias; TCA, Tricyclic antidepressants; VAS, Visual Analog Scale. associated cranial autonomic features, other associated features (nausea, vomiting, photophobia, phonophobia, aural fullness, and behavioral changes) during attacks and treatment modalities were all recorded. The severity of headache was estimated using a Visual Analog Scale (VAS) to indicate the maximum intensity of pain by asking the patients to make a mark on a $10-\mathrm{cm}$ line labeled with "no pain" at the zero end and "the worst pain possible" at the other $(12,13)$.

This study was approved by ethical committee of Kuwait ministry of health. Written informed consent was obtained from all participant before using their information.

\section{Statistical Analysis}

All measurements were reported as mean $\pm \mathrm{SD}$. Categorical variables were compared using the Chi-square test, and continuous variables were compared using Student's $t$-test. SPSS for Windows, Version 16.0, was used for statistical analyses with the significance level set at $P=0.05$.

\section{RESULTS}

A total of 2,782 headache patients were evaluated at our Headache Clinic during the period between January 2016 till September 2018. Forty-six patients were diagnosed with $\mathrm{CH}$ which constitute $1.7 \%$ of all headache patients (Figure 1) and $0.1 \%$ of all patients $[45,986]$ who are reviewed at our Neurology clinics in that period.

\section{Demographic Characteristics}

A total of 46 patients were included, 43 [94.5\%] were males and $3[6.5 \%]$ were females, giving a M:F ratio of 15.3:1. Mean age of the patients was $40.1 \pm 10.7$ years (range 23-69 years). Mean age at disease onset was 29 years (range 20-49 years). Kuwaiti nationality 32 [69.6\%] was the most prevalent in our cohort. Twenty-nine [63\%] patients were smokers, while only 3 patients reported alcohol intake 6.5\%. Family history of $\mathrm{CH}$ in a first or second degree relative was reported in only 3 [6.5\%] patients (Table 1).

\section{Headache Characteristics}

Most of our patients had episodic CH 39 [84.8\%], while only 7 [15.2\%] had chronic $\mathrm{CH}$, interestingly all the chronic patients were smokers. $\mathrm{CH}$ was strictly unilateral in all our patients with equal right and left side affection. Pain was predominantly affecting peri-orbital and temporal region 43 [93.5\%], frontal 2 [4.3\%], and occipital 1 [2.2\%]. Pain intensity was described by the majority as being severe in 41 [89.1\%] patients and moderatelysevere in 5 [10.9\%] patients. VAS for pain severity was used in all our patients, the score ranged from 7 to 10 with a median of 8.5. Character of pain was throbbing in 35 [76.1\%] patients, followed with stabbing 6 [13\%], burning $4(8.7 \%)$, and boring in only one $2.2 \%$ patient. The duration of the cluster bouts ranged from 2 to 12 weeks with a mean of 6 weeks. The duration of the attack ranged from 15 to $180 \mathrm{~min}$ with a mean of $60 \mathrm{~min}$. The number of attacks per day ranged from 2 to 10 attacks with a mean of 5 attacks/day. Regarding the frequency of cluster periods, the 


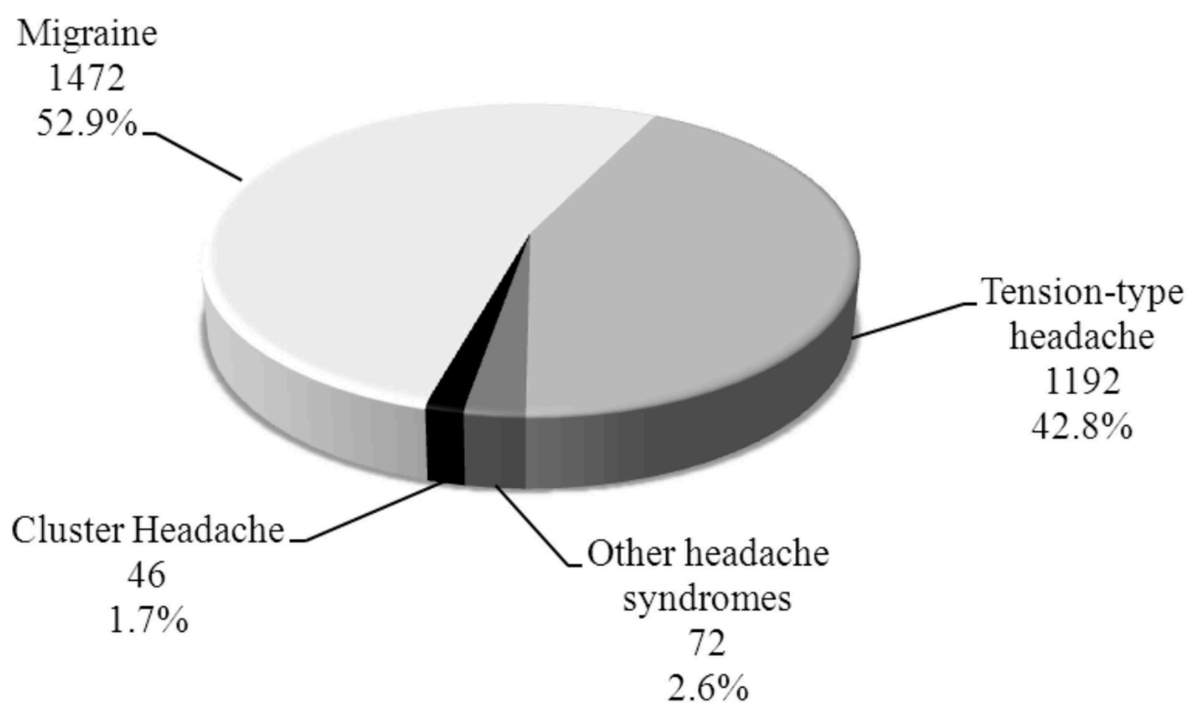

FIGURE 1 | Distribution of headache cases in outpatient population ( $n=2,782)$.

TABLE 1 | Demographic profile $(n=46)$.

\begin{tabular}{lc}
\hline & M \pm SD/No. (\%) \\
\hline Age (years) & \\
Mean \pm SD & $40.1 \pm 10.7$ \\
Age at the onset (years) & $29(20-49)$ \\
Mean (Range) & \\
Gender & $43(94.5)$ \\
Male & $3(6.5)$ \\
Female & \\
Nationality & $32(69.6)$ \\
Kuwait & $9(19.6)$ \\
Egypt & $3(6.5)$ \\
Saudi & $1(2.2)$ \\
Syria & $1(2.2)$ \\
India & $29(63)$ \\
Smoking & $3(6.5)$ \\
Alcohol intake & $3(6.5)$ \\
Family history & \\
\hline
\end{tabular}

majority had one bout per year; 25 [54.3\%] patients, every 2 years in 10 [21.7\%], every 3 years in 2 [4.3\%], every 3 months in $4[8.7 \%]$, every month in 4 [8.7\%], and every 6 months in only one $(2.2 \%)$ patient. Seasonal predilection was observed in our patients; the most frequent season was Autumn 22 [47.8\%] patients, followed with Winter 15 [32.6\%], Spring 7 [15.2\%], and the least frequent was Summer 2 [4.3\%] patients. These cluster periods occurred mainly in October, December, September, and November (Figure 2).

The time taken to diagnose ranged from $<1$ to 12 years with a median of 4 years. The total duration of the disease among our patient ranged from 2 to 30 years with a mean of 10 years. Among cranial autonomic features, rhinorrhea and nasal congestion were found in all 46 [100\%] patients, tearing was found in 45 [97.8\%] patients, conjunctival injection in 44 [95.7\%], ptosis and miosis were found in 10 (21.7\%), while facial sweating in only 4 [8.7\%] patients. Other associated features during the clusters were nausea with or without vomiting in $28(60.9 \%)$ patients, photophobia and phonophobia in 23 [50\%] patients, of which 20 [43.5\%] patients reported it as unilateral. Agitation during the attacks was reported by 41 [89.1\%] patients. Aural fullness was reported by 28 [60.9\%] patients.

Neurological examination between the cluster attacks was normal in all patients $100 \%$. All patients underwent magnetic resonance (MR) imaging of the brain; 41 [89.1\%] patients were normal, non-specific white matter changes (WM) were reported in $4(8.7 \%)$ patients, and one patient $2.2 \%$ had incidental sellar cyst.

In our cohort, some patients received the diagnosis of another type of headache in addition to $\mathrm{CH}, 8$ [17.4\%] patients had migraine, 4 [8.7\%] patients had tension-type headache and one patient $2.2 \%$ had mixed type of migraine and tension headache. Two patients were diagnosed with secondary headache; one patient had a sellar cyst and another one had foreign bodies in the skull and left maxillary sinus during the Gulf War (Table 2).

\section{Chronic CH}

We studied the relationship between different headache characteristics and chronicity in $\mathrm{CH}$. Age of chronic $\mathrm{CH}$ patients $(48.3 \pm 11.3)$ was higher than episodic $\mathrm{CH}$ patients $(38.7 \pm 10.1)$, the difference was statistically significant $(P=0.027)$.

Age at disease onset was also higher in chronic $\mathrm{CH}$ patients; 31 years (24-46) compared to episodic $\mathrm{CH}$ patients; 27 years (20$49)$ with a statistically significant difference $(P=0.036)$. Smoking was reported by $100 \%$ of chronic cases compared to $56.4 \%$ of episodic cases which was statistically significant $(P=0.036)$. 


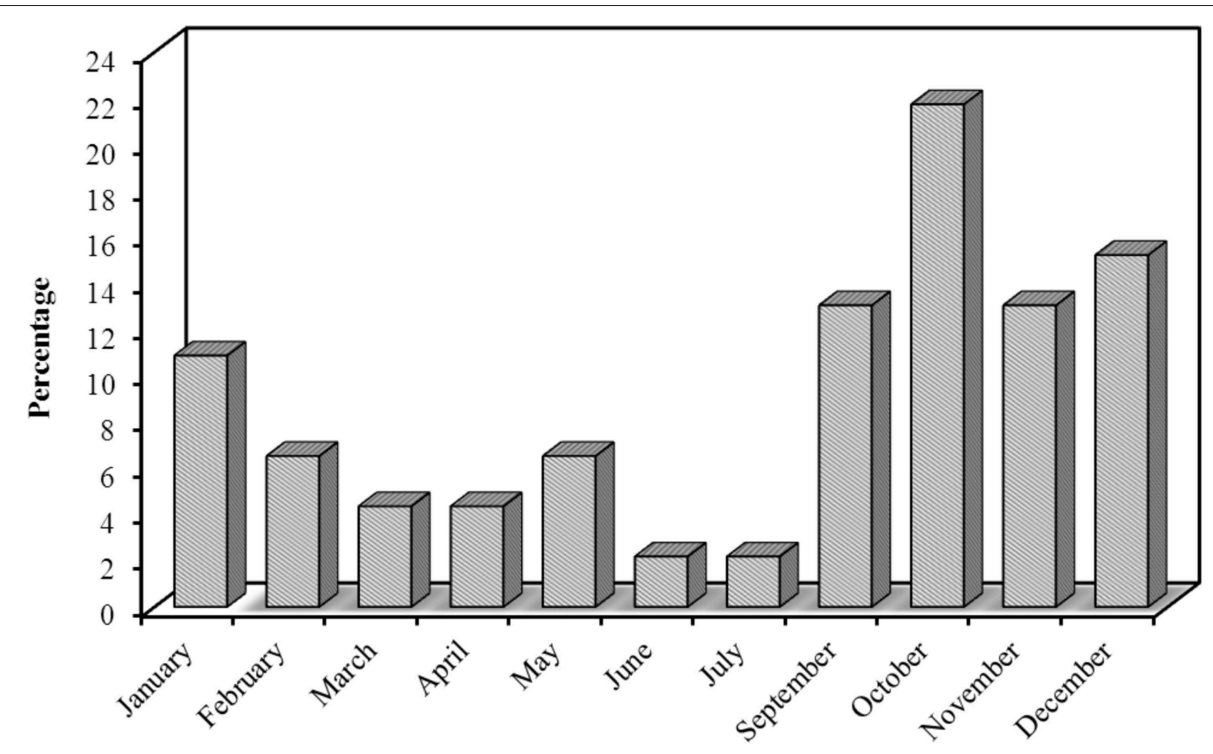

FIGURE 2 | Distribution of the studied cases according to month ( $n=46)$.

The mean time taken till diagnosis was 4 years in episodic $\mathrm{CH}$ and 6 years in chronic $\mathrm{CH}$ which was statistically significant $(P=0.026)$ (Table 3).

\section{Treatment}

Treatment was individualized for each patient. During acute attacks, all our patients received high-flow oxygen. Steroids either Dexamethasone or Prednisone were given to 45 [97.8\%] patients. Triptans were given to 37 [80.4\%] patients; sumatriptan being the most commonly used by $32(69.6 \%)$ patients. Forty patients $87 \%$ reported using non-steroidal anti-inflammatory drugs (NSAIDs) during acute attacks. For preventive treatment, the most common drug used was topiramate in 24 [52.2\%] patients followed by verapamil in 22 [47.8\%] and lithium in one patient $2.2 \%$. Other drugs used included Tricyclic antidepressants (TCA) in 4 [8.7\%] patients and valproic acid in 1 [2.2\%]. Greater occipital nerve block (GONB) and Botulinum toxin (BTX) were given to $6[13.0 \%]$ patients each. Only one patient $2.2 \%$ in our cohort underwent Percutaneous radiofrequency ablation (RFA) of the sphenopalatine ganglion (SPG) due to poor response to medical treatment (Table 4).

\section{DISCUSSION}

$\mathrm{CH}$ data from our region in general are scarce in literature and no data were previously published from gulf countries $(10,11)$.

Prevalence of $\mathrm{CH}$ in our cohort was $1.7 \%$ of all headache patients evaluated in our clinic which matches with the prevalence found in other clinic-based studies from Egypt 1.7\% (14), China 1.7\% (15), Pakistan 1.6\% (16), and Ethiopia $1.3 \%$ (17). Accurate estimation of $\mathrm{CH}$ prevalence is difficult because of its low prevalence in general population in comparison to migraine and tension-headache (18). $\mathrm{CH}$ constituted $0.1 \%$ of all patients evaluated in our neurology outpatient clinics during the duration of the study, while in china the frequency of $\mathrm{CH}$ in the neurological outpatient clinic population was $0.2 \%$ (15). The prevalence of $\mathrm{CH}$ in community-based studies ranged from 0.1 to $0.2 \%(19,20)$.

$\mathrm{CH}$ attacks affect patients in their most productive years with negative results on their quality of life $(9,15)$. The mean age of our patients was $40.1( \pm 10.7)$ years and the mean age at onset was $29( \pm$ SD 5.3) years. Our results are in consistence with previous studies $(15,21,22)$ the mean age of onset in China (27 \pm 8$)(15)$, in Taiwan (26.9) years (21), in Japan (31) years (22), and in USA $36 \%$ of patients were $20-30$ years old (23).

$\mathrm{CH}$ was more common in males than in females in our cohort with male-to-female ratio of 15.3:1 which is higher than any figure published before. The male-to-female ratio is variable in literature being generally higher in Asian studies and lower in Western studies ranging from $14: 1$ to $2.5: 1(15,21,22)$. In patient sample studies, this ratio ranged between ranged between 2.5:1 and 14:1 (20, 21, 24-27). In the Vågå study of headache epidemiology including $\mathrm{CH}$, female to male was one to six (28).

The high male to female ratio in our cohort may be related to the conservative nature of our population with low smoking prevalence among women and alcohol being prohibited. Another possible explanation can be related to the climate and latitude effect on $\mathrm{CH}$ which is not well studied so far.

Smoking is considered a significant risk factor for developing and triggering $\mathrm{CH}(21,23)$. In our cohort, more than $60 \%$ were smokers. The majority of US $\mathrm{CH}$ patients had a history of smoking ( $73 \%$ total patients, with $51 \%$ actively smoking at time of $\mathrm{CH}$ onset) (18). Schürks and Diener reported that $94 \%$ of the patients were smokers, with an average of 32 cigarettes smoked per day (29). Tiraferri et al. found $90 \%$ of $\mathrm{CH}$ patients had a prolonged history of smoking (30). All chronic $\mathrm{CH}$ patients in our cohort were smokers. Current smoking history was significantly more prevalent among chronic $\mathrm{CH}$ patients 
TABLE 2 | Characters of headache pain $(n=46)$.

No. (\%)/Mean (Range)

\section{Type of $\mathbf{C H}$}

Episodic

Chronic

Side

Right

Left

Site

Periorbital-temporal

Frontal

Occipital

Season

Autumn

Winter

Spring

Summer

\section{Severity}

Moderate-severe

Severe

VAS Severity Scale

Median (range)

7

8

9

10

\section{Character}

Throbbing

Stabbing

Burning

Boring

Duration of attack (min)

Duration of the disease (years)

Duration of cluster bout (weeks)

Frequency

Once/1 month

Once/3 months

Once/6 months

Once/1 year

Once/2 years

Once/3 years

Age of disease onset (years)

Time taken till diagnosis (years)

Associated symptoms

Rhinorrhea

Nasal congestion

Lacrimation

Aural fullness

Conjunctival injection

Facial sweating

Ptosis

Miosis

Agitation
$39(84.8)$

7 (15.2)

$23(50)$

23 (50)

43 (93.5)

2 (4.3)

$1(2.2)$

22 (47.8)

15 (32.6)

7 (15.2)

2 (4.3)

5 (10.9)

$41(89.1)$

$8.5(7-10)$

3 (6.5)

$20(43.5)$

19 (41.3)

4 (8.7)

35 (76.1)

6 (13)

4 (8.7)

1 (2.2)

60 (15-180)

$10(2-30)$

$6(2-12)$

4 (8.7)

4 (8.7)

1 (2.2)

25 (54.3)

$10(21.7)$

2 (4.3)

29 (20-49)

$4(0-12)$

46 (100)

46 (100)

$45(97.8)$

22 (47.8)

44 (95.7)

$4(8.7)$

$10(21.7)$

41 (89.1)
$10(21.7)$
TABLE 2 | Continued

\begin{tabular}{lc}
\hline & No. (\%)/Mean (Range) \\
\hline Nausea/Nomiting & $28(60.9)$ \\
Photophobia \& phonophobia & $23(50)$ \\
Associated headaches & \\
No & $33(71.7)$ \\
Migraine & $8(17.4)$ \\
TTH & $4(8.7)$ \\
Examination/Normal & $46(100)$ \\
MRI/MRA & $41(89.1)$ \\
Normal & $4(8.7)$ \\
Non-specific WM changes & $1(2.2)$ \\
Seller cyst & \\
\hline
\end{tabular}

$\mathrm{CH}$, Cluster Headache; VAS, Visual Analog Scale; TTH, tension type headache; MRI, Magnetic resonance image; MRA, Magnetic resonance angiography; WM, white matter.

TABLE 3 | Association between type of $\mathrm{CH}$ and headache characteristics.

\begin{tabular}{lccc}
\hline & \multicolumn{2}{c}{ Type of CH } & $p$ \\
\cline { 2 - 3 } & Episodic $(\boldsymbol{n}=39)$ & Chronic $(\boldsymbol{n}=7)$ & \\
\hline Age & $38.9 \pm 9.8$ & $48.1 \pm 11.3$ & $0.029^{*}$ \\
Smoking & $22(56.4 \%)$ & $7(100.0 \%)$ & $0.036^{*}$ \\
Time taken till diagnosis & $4(0-10)$ & $6(3-12)$ & $0.026^{*}$ \\
Age of onset of the disease & $27(20-49)$ & $31(24-46)$ & $0.036^{*}$ \\
\hline
\end{tabular}

${ }^{\star} P<0.05$ is significant.

more than episodic $\mathrm{CH}$ patients [75 vs. $65 \%$ ] in a British study (31) and 70.8 vs. $65.2 \%$ in a German study (26). These findings point to not only the association between smoking and $\mathrm{CH}$, but to a possible causal association that deserves mentioning as well (26), moreover, improvement after reducing their cigarette consumption strongly support such hypothesis (29). Alcohol intake as another known trigger (29) was reported by only 6.5\% of our patients as its consumption is prohibited in Kuwait.

Prevalence of $\mathrm{CH}$ in the same family is variable in different studies. We reported $6.5 \%$ of our patients have history of headache in at least one of their family members. Positive history reported in 1.9-6.7\% in Bharar et al patients (24), other studies showing that $7 \%$ of $\mathrm{CH}$ patients had a positive family history of headache (31), while Rozen and Fishman reported that around $18 \%$ of $\mathrm{CH}$ patients in US had positive family history (23). CH risk in first-degree relatives is $5-18$ times higher, and in second degree relatives, 1-3 times higher as compared to the general population $(18,30)$.

The majority of our cases had episodic $\mathrm{CH} 84.4 \%$ which is in agreement with Japanese studies that reported a low prevalence of chronic $\mathrm{CH}$ (1.2-2.9\%) (22), while other studies from Asia reported no chronic cases at all $(15,21)$. Large-scale populationbased studies are necessary to determine if chronic $\mathrm{CH}$ is truly less prevalent in Kuwait as seen in other Asian populations.

All of the patients had a strictly unilateral headache with no side predominance, Xie et al. and Wang et al. reported right-sided predominance $(15,21)$, other studies reported side shift in some of their patients $(23,26)$. 
TABLE 4 | Treatment modalities $(n=46)$.

\begin{tabular}{lc}
\hline & No. (\%) \\
\hline ACUTE TREATMENT & \\
High flow oxygen & $46(100)$ \\
Steroids & $45(97.8)$ \\
Triptans & $37(80.4)$ \\
NSAID & $40(87)$ \\
PROPHYLACTIC TREATMENT & \\
Topiramate & $24(52.2)$ \\
Verapamil & $22(47.8)$ \\
TCA & $4(8.7)$ \\
Lithium & $1(2.2)$ \\
Valproic acid & $1(2.2)$ \\
OTHERS & \\
GONB & $6(13)$ \\
BTX & $6(13)$ \\
SPG RFA & $1(2.2)$
\end{tabular}

NSAID, Non-steroidal anti-inflammatory drugs; TACs, Trigeminal Autonomic Cephalalgias; GONB, Greater occipital nerve block; BTX, botulinum toxin; RFA, Radiofrequency ablation; SPG, Sphenopalatine ganglio; nTCA, Tricyclic antidepressants; RFA, Radiofrequency ablation.

Seasonal predilection is common in $\mathrm{CH}$ which is considered a circadian-based syndrome (18). In our study, the majority of our patients presented in autumn and winter with the highest prevalence in October and December, the least presentation was in the summer. This pattern was first noted by Ekbom and Kudrow and was repeatedly seen over the years $(18,32,33)$.

It is well known that $\mathrm{CH}$ is one of the worst headaches and this was agreed upon by $89.1 \%$ of our patients who reported having severe rather than moderately severe headache with a mean VAS of 8.5. These results were similar to another clinic-based study from China where the mean VAS was 8.2 (15).

The associated autonomic symptoms which are the defining feature of $\mathrm{CH}$ were found in all of our patients similar to other studies. Rhinorrhea $100 \%$ and nasal congestion $100 \%$ were the most reported symptoms in all of our patients followed by conjunctival injection and lacrimation while ptosis and miosis were the least reported. Lacrimation was the most reported associated autonomic symptom in some studied $(13,34)$, and less frequens in other studies (15). A sense of restlessness or agitation, which differentiate $\mathrm{CH}$ from migraine was seen in $89.1 \%$ of our patients which is in agreement with previous studies that reported it ranged between 67.6 and 93\% $(22,24,26)$.

Photophobia and/or phonophobia were reported in half of our patients and interestingly most of them reported it being unilateral at the side of pain which was previously reported by Irimia et al. (35).

The mean time taken till accurate diagnosis in our cohort was 4 years. In a Dutch study the median time before a proper diagnosis of $\mathrm{CH}$ was 3 years (36), Klapper et al. found a time delay of 6.6 years in a US population (37), Rozen et al. study showed a 5 years delay or longer in around half of the patients (28). Factors that may lead to delay are the presence of photophobia or phonophobia, nausea or vomiting which may lead to misdiagnosis as migraine, an episodic attack pattern and a younger age at onset (36). In hospital bases study of Cristina Voiticovschi-Iosob showed that the mean interval between onset of the disease and first consultation at a headache center was $4.1 \pm 5.6$ years. Their patients had consulted different specialists prior to receiving their $\mathrm{CH}$ diagnosis: neurologists (49\%), primary care physicians (35\%), ENT specialists (10\%), dentists (3\%). Misdiagnoses at first consultation were recorded in $77 \%$ of the cases: trigeminal neuralgia (22\%), migraine without aura (19\%), sinusitis (15\%). The average "diagnostic delay" was 5.3 \pm 6.4 years (38). Nine (19.5\%) patients in our cohort were initially misdiagnosed as migraine that changed to $\mathrm{CH}$ over the years.

Treatment of $\mathrm{CH}$ in our cohort followed an individualized approach. During acute attacks, all our patients received high flow oxygen with good response. The majority also received steroids $79.8 \%$ either oral or parenteral during the attacks and reported using over the counter non-steroidal anti-inflammatory drugs. Sumatriptan was the commonest triptan to be used as it has both oral and subcutaneous route of administration. Topiramate was the commonest prophylactic treatment used followed by verapamil. BTX injection and GONB were both given to some of our patients who showed inadequate response to medical treatment and were found to be a safe and effective option in several studies with good outcome (39-41). RFASPG was performed for only one patient with secondary $\mathrm{CH}$ who failed medical treatment and he showed favorable outcome (3).

\section{LIMITATIONS OF THE STUDY}

Our study had some limitations being a hospital-based study including: the small sample size and the lack of impact of $\mathrm{CH}$ on our patient's occupation and quality of life. Our cohort is small because $\mathrm{CH}$ is uncommon primary headache disorder in addition that it might be misdiagnosed as sinus headache by general practioner before referral to our specialized headache clinic. Health service in Kuwait start in primary care, then refractory cases are referred to secondary and tertiary services.

\section{STRENGTH OF OUR STUDY}

This study has the strength of providing data from Kuwait where the prevalence of $\mathrm{CH}$ could be different from that in the general population, perhaps as a consequence of traditions and religion (e.g., smoke and alcohol).

\section{CONCLUSION}

This study describes the demographic and clinical characteristics of $\mathrm{CH}$ in a neurology outpatient in Kuwait. Our results coincided 
with other clinical studies published in many aspects, including the prevalence and clinical characteristics of $\mathrm{CH}$. However, it was different in the highest proportion of men and in a less positive family history. We found that smoking is a significant risk factor for chronicity in patients with $\mathrm{CH}$ in addition to advanced age, higher age at disease onset and a longer time taken till diagnosis. Further community-based studies are needed in the gulf region to give better understanding of $\mathrm{CH}$ in this part of the world.

\section{DATA AVAILABILITY}

Data are available at neurology department, Ibn Sina hospital, Kuwait.

\section{ETHICS STATEMENT}

Our research was carried out according to ethical guidelines of Kuwait Ministry of Health.

\section{REFERENCES}

1. Headache Classification Committee of the International Headache Society (IHS). The International classification of headache disorders, 3rd edition (beta version). Cephalalgia. (2013) 33:629-808. doi: 10.1177/0333102413485658

2. Nesbitt AD, Goadsby PJ. Cluster headache. BMJ. (2012) 344:e2407. doi: 10.1136/bmj.e2407

3. Hoffmann J, May A. Diagnosis, pathophysiology, and management of cluster headache. Lancet Neurol. (2017) 17:7583. doi: 10.1016/S1474-4422(17)30405-2

4. Newman LC. Trigeminal autonomic cephalalgias. CONTINUUM. (2015) 21(4 Headache):1041-57. doi: 10.1212/CON.00000000000 00190

5. Barloese M, Lund N, Petersen A, Rasmussen M, Jennum P, Jensen R. Sleep and chronobiology in cluster headache. Cephalalgia. (2015) 35:96978. doi: 10.1177/0333102414564892

6. Barloese MC. Neurobiology and sleep disorders in cluster headache. $J$ Headache Pain. (2015) 16:78. doi: 10.1186/s10194-015-0562-0

7. Wilbrink LA, Louter MA, Teernstra OP, van Zwet EW, Huygen FJ, Haan J, et al. Allodynia in cluster headache. Pain. (2017) 158:11137. doi: 10.1097/j.pain.0000000000000891

8. Schor LI. Cluster headache: investigating severity of pain, suicidality, personal burden, access to effective treatment, and demographics among a large International survey sample. Cephalalgia. (2017) 37:172. doi: 10.1177/0333102417719574

9. Choi YJ, Kim BK, Chung PW, Lee MJ, Park JW, Chu MK, et al. Impact of cluster headache on employment status and job burden: a prospective cross-sectional multicenter study. J Headache Pain. (2018) 19:78. doi: 10.1186/s10194-018-0911-x

10. Benamer HTS, Deleu D, Grosset D. Epidemiology of headache in Arab countries. J Headache Pain. (2010) 11:1-3. doi: 10.1007/s10194-009-0173-8

11. Al-Hashel JY, Ahmed SF, Alroughani R. Prevalence of primary headache disorders in Kuwait. Neuroepidemiology. (2017) 48:138-46. doi: 10.1159/000478892

12. Hayes MHS, Paterson DG. Experimental development of the graphic rating method. Psychol Bull. (1921) 18:98-9.

13. Haefeli M, Elfering A. Pain assessment. Eur Spine J. (2006) 15:S1724. doi: 10.1007/s00586-005-1044-X

14. El-Sherbiny NA, Masoud M, Shalaby NM, Shehata HS. Prevalence of primary headache disorders in Fayoum Governorate, Egypt. J Headache Pain. (2015) 16:85. doi: 10.1186/s10194-015-0569-6

\section{CONSENT FOR PUBLICATION}

All authors have read and approved the submitted manuscript. Our manuscript has not been submitted elsewhere nor published elsewhere.

\section{AUTHOR CONTRIBUTIONS}

JA-H designed the study and reviewed the manuscript. II performed data collection, statistical analysis and drafted the manuscript. DY performed data collection and drafted the manuscript. SA drafted, criticized and reviewed the manuscript. PG reviewed the manuscript. All authors read and approved the final manuscript.

\section{ACKNOWLEDGMENTS}

We would like to thank the study participants and the administrative department in Ibn Sina Hospital for actively participating in the study.

15. Xie Q, Huang Q, Wang J, Li N, Tan G, Zhou J. Clinical features of cluster headache: an outpatient clinic study from China. Pain Med. (2013) 14:8027. doi: 10.1111/pme.12101

16. Murtaza M, Kisat M, Daniel H, Sonawalla AB. Classification and clinical features of headache disorders in Pakistan: a retrospective review of clinical data. PLoS ONE. (2009) 4:e5827. doi: 10.1371/journal.pone.0005827

17. Haimanot RT, Seraw B, Forsgren L, Ekbom K, Ekstedt J. Migraine, chronic tension-type headache, and cluster headache in an Ethiopian rural community. Cephalalgia. (1995) 15:4828. doi: 10.1046/j.1468-2982.1995.1506482.x

18. Wei DY, Ong JJ, Goadsby PJ. Cluster headache: epidemiology, pathophysiology, clinical features, and diagnosis. Ann Indian Acad Neurol. (2018) 21(Suppl 1):S3. doi: 10.4103/aian.AIAN_349_17

19. Torelli P, Beghi E, Manzoni GC. Cluster headache prevalence in the Italian general population. Neurology. (2005) 64:46974. doi: 10.1212/01.WNL.0000150901.47293.BC

20. Fischera M, Marziniak M, Gralow I, Evers S. The incidence and prevalence of cluster headache: a meta-analysis of population-based studies. Cephalalgia. (2008) 28:614-8. doi: 10.1111/j.1468-2982.2008.01592.x

21. Lin KH, Wang PJ, Fuh JL, Lu SR, Chung CT, Tsou HK, et al. Cluster headache in the Taiwanese-a clinic-based study. Cephalalgia. (2004) 24:6318. doi: 10.1111/j.1468-2982.2003.00721.x

22. Imai N, Yagi N, Kuroda R, Konishi T, Serizawa M, Kobari M. Clinical profile of cluster headaches in Japan: low prevalence of chronic cluster headache, and uncoupling of sense and behaviour of restlessness. Cephalalgia. (2011) 31:628-33. doi: 10.1177/0333102410391486

23. Rozen TD, Fishman RS. Cluster headache in the United States of America: demographics, clinical characteristics, triggers, suicidality, and personal burden. Headache. (2012) 52:99-113. doi: 10.1111/j.1526-4610.2011.02028.x

24. Bahra A, May A, Goadsby PJ. Cluster headache: a prospective clinical study with diagnostic implications. Neurology. (2002) 58:354-61. doi: 10.1212/WNL.58.3.354

25. El Amrani M, Ducros A, Boulan P, Aidi S, Crassard I, Visy JM, et al. Familial cluster headache: a series of 186 index patients. Headache. (2002) 42:974-7. doi: 10.1046/j.1526-4610.2002.02226.x

26. Schürks M, Kurth T, De Jesus J, Jonjic M, Rosskopf D, Diener HC. Cluster headache: clinical presentation, lifestyle features, and medical treatment. Headache. (2006) 46:1246-54. doi: 10.1111/j.1526-4610.2006.00534.x

27. D’Alessandro R, Gamberini G, Benassi G, Morganti G, Cortelli P, Lugaresi E. Cluster headache in the Republic of San Marino. Cephalalgia. (1986) 6:159-62. doi: 10.1046/j.1468-2982.1986.0603159.x 
28. Sjaastad O, Bakketeig LS. Cluster headache prevalence. Vågå study of headache epidemiology. Cephalalgia. (2003) 23:52833. doi: 10.1046/j.1468-2982.2003.00585.x

29. Schürks M, Diener HC. Cluster headache and lifestyle habits. Current pain and headache reports. (2008) 12:115-21. doi: 10.1007/s11916-008-0022-5

30. Tiraferri I, Righi F, Zappaterra M, Ciccarese M, Pini LA, Ferrari A, et al. Can cigarette smoking worsen the clinical course of cluster headache? J Headache Pain. (2013) 14(S1):P54. doi: 10.1186/1129-2377-14-S1-P54

31. Russell MB. Epidemiology and genetics of cluster headache. Lancet Neurol. (2004) 3:279-83. doi: 10.1016/S1474-4422(04)00735-5

32. Ekbom K. Patterns of cluster headache with a note on the relations to angina pectoris and pepticulcer. Acta Neurol Scand. (1970) 46:225-237.

33. Kudrow L. The cyclic relationship of natural illumination to cluster period frequency. Cephalalgia. (1987) 7(6_suppl):768. doi: 10.1177/03331024870070S623

34. Lai TH, Fuh JL, Wang SJ. Cranial autonomic symptoms in migraine: characteristics and comparison with cluster headache. J Neurol Neurosurg Psychiatry. (2009) 80:1116-9. doi: 10.1136/jnnp.2008.157743

35. Irimia $\mathrm{P}$, Cittadini E, Paemeleire $\mathrm{K}$, Cohen AS, Goadsby PJ. Unilateral photophobia or phonophobia in migraine compared with trigeminal autonomic cephalalgias. Cephalalgia. (2008) 28:626-30. doi: 10.1111/j.1468-2982.2008.01565.x

36. Van Vliet JA, Eekers PJ, Haan J, Ferrari MD. Features involved in the diagnostic delay of cluster headache. J Neurol Neurosurg Psychiatry. (2003) 74:1123-5. doi: 10.1136/jnnp.74.8.1123

37. Klapper JA, Klapper A, Voss T. The misdiagnosis of cluster headache: a nonclinic, population-based, Internet survey. Headache. (2000) 40:7305. doi: 10.1046/j.1526-4610.2000.00127.x
38. Voiticovschi-Iosob C, Allena M, De Cillis I, Nappi G, Sjaastad O, Antonaci F. Diagnostic and therapeutic errors in cluster headache: a hospital-based study. J Headache Pain. (2014) 15:56. doi: 10.1186/1129-237 7-15-56

39. Peres MF, Stiles MA, Siow HC, Rozen TD, Young WB, Silberstein SD. Greater occipital nerve blockade for cluster headache. Cephalalgia. (2002) 22:520-2. doi: 10.1046/j.1468-2982.2002.00410.x

40. Busch V, Jakob W, Juergens T, Schulte-Mattler W, Kaube H, May A. Occipital nerve blockade in chronic cluster headache patients and functional connectivity between trigeminal and occipital nerves. Cephalalgia. (2007) 27:1206-14. doi: 10.1111/j.1468-2982.2007.0 1424.x

41. Gaul C, Roguski J, Shanib H, Totzeck A, Görlinger K, Diener $\mathrm{HC}$, et al. Efficacy and safety of occipital nerve blocks in cluster headache: a prospective observational study. J Headache Pain. (2013) 14(S1):P60. doi: 10.1186/1129-2377-14-S1-P60

Conflict of Interest Statement: The authors declare that the research was conducted in the absence of any commercial or financial relationships that could be construed as a potential conflict of interest.

Copyright (c) 2019 Al-Hashel, Ibrahim, Youssry, Ahmed and Goadsby. This is an open-access article distributed under the terms of the Creative Commons Attribution License (CC BY). The use, distribution or reproduction in other forums is permitted, provided the original author(s) and the copyright owner(s) are credited and that the original publication in this journal is cited, in accordance with accepted academic practice. No use, distribution or reproduction is permitted which does not comply with these terms. 